\title{
Sustainability Skills: The Case of a Portuguese University
}

\author{
Thiago Antonio Beuron, Lucas Veiga Ávila, \\ Luciana Londero Brandli, Filipe Jorge Ribeiro de Almeida, \\ Lúcia Rejane da Rosa Gama Madruga \\ and Eduardo Jorge Gonçalves Barata
}

\begin{abstract}
Based on the state of the art on universities and sustainability, an attempt was made to understand the development of a Portuguese university on the perspective of sustainability, by analyzing the necessary skills for such sustainability. The design used for this research was the case study design. The data collection occurred between September and November 2014, and a data collection protocol elaborated from the theory on sustainability in universities was used. Through observations, interview and analysis of documents as evidence sources, the most expressive results highlight that the University of Coimbra-UC uses sustainability concepts that go beyond teaching and learning. The institution aims to develop, through programs, contests to gather ideas from students and business consultancies, a philosophy that would emerge
\end{abstract}

\footnotetext{
T.A. Beuron ( $\bowtie)$

Federal University of Pampa, Quaraí, Brazil

e-mail: tbeuron@gmail.com

L.V. Ávila · L.R. da Rosa Gama Madruga

Federal University of Santa Maria, Santa Maria, Brazil

e-mail: admlucasveiga@gmail.com
}

L.R. da Rosa Gama Madruga

e-mail: luciagm@ufsm.br

\author{
L.L. Brandli \\ University of Passo Fundo, Passo Fundo, Brazil \\ e-mail: brandli@upf.br
}

F.J.R. de Almeida · E.J.G. Barata

Faculty of Economics, University of Coimbra, Coimbra, Portugal

e-mail: falmeida@fe.uc.pt

E.J.G. Barata

e-mail: ebarata@fe.uc.pt 
from the sustainability skills inside the campus, curriculum and community. Through the environmental management of the campus, UC promotes energy savings, preservation of resources, waste reduction, preservation of the property, gas and water as to the energy efficiency plan, and the creation of new courses for sustainable development. It is observed that the university has the efficient sustainability skills as to the analyzed dimensions, and they were monitored as to its goals and programs. With lower emphasis, due to the secular characteristics, the sustainability actions occur on the structures that require alternatives to meet new sustainability concepts, which have been introduced into green universities.

\section{Keywords}

Skills · Sustainability skills · Universities - Sustainability

\section{Introduction}

The Decade of Education for Sustainable Development (2005-2014) was suggested to promote a social momentum that would engage educators in the task of make people aware on the planetary emergency situation and qualify them for the decision-making processes in order to stop environmental degradation. In general, the changes to the curriculums, teaching practices and research do not yet meet the demands of the global-scale problems, that require holistic approaches (Vilches 2012). Universities may be seen as laboratories to practice sustainability initiatives (Thomashow 2014).

As a complex type of organization, universities are continuously demanded to contribute with the discussion on sustainability, mainly since they are an educational environment, not only a productive one, such as industries and other sectors. Through universities, it is expected to promote new collective postures that depend on a change of awareness, new knowledge, and balance and dialogue with society.

The consensus indicated by UNESCO (2014) is that the key questions to reach the sustainable development go through teaching and learning. Themes such as climate change, reduction of the risk of disasters, sustainable lifestyles, biodiversity or poverty reduction are characterized by uncertainty, complexity and systemic interconnection. As such, they demand more participative teaching and learning methods, such as critical thinking, through which it is possible to work with collaborative decision-making scenarios, qualifying the academic communities for the sustainability context.

From a report elaborated by a committee of experts from around the world, the answer to the Decade of Education for Sustainable Development is the need for innovation in education, in order to promote it as a tool for society to move toward sustainability (UNESCO 2014). This report suggests that the process of creation and reorientation of sustainable development policies, programs and plans occurs in the Member States in a rather unequal manner. 
The final report of UNESCO (2014) also discusses the need for the development of skills and abilities on students in order to promote the value of sustainability for businesses and to work focused on a global economy, which is more inclusive and sustainable, namely on the level of MBAs, post-graduation courses and short-term courses for executives. The research results emphasize the gap between the sustainability perspectives that are taught at schools and that are required on the market by companies, indicating a need to further establish a clear set of skills to be used in companies, in order to reinforce the skills demanded by the context (UNESCO 2014).

The issue of sustainability in Higher Education Institutions has been marked by a series of events, statements and resolutions that try to comprehend variables that need to be included in the daily life of the campus. This study explores the way in which a Portuguese University develops the perspective of sustainability, by analyzing the essential skills for sustainability that make this organization stand out. Specifically, the analysis and reflection focus on how the University of Coimbra contributes to build sustainability skills, which are the essential skills that make this organization stand out, or which are the representative skills in the campus, curriculum and the community.

Initially, the article approaches the literature on sustainability skills, describes the method that works as the basis for research, shows the case and the evidence found and provides the conclusions.

\section{Sustainability Skills}

Up to the end of the Middle Age, the term skills referred to the judicial area, which used this expression to refer to the ability of some institution or individual to appreciate and/or judge certain issues. From that, the concept was broadened as the social acknowledgement on the capacity of an individual to speak in relation to any subject. Then, it was used in more general terms to qualify any individual with the ability to conduct a certain work (Isambert-Jamati 1997; Brandão and Guimarães 2001).

On the organizational theory, skills are considered fundamental for the competition among organizations, and they are seen as the positive result of the efforts of individuals and organizations in relation to individual and/or organizational objectives. According to Draganidis and Mentzas (2006), this result is seen as the combination of knowledge, behaviors and abilities that confer someone an efficiency potential to perform a certain task.

The organizational skill integrates specific functional and technological abilities in larger sets of abilities, such as the creation and management of extremely complex products or services that are possible by understanding the core of the phenomena. It is an iterative and progressive set of understandings and skills by the employees, and it occurs within the organizational structure, and not individually (Edgar and Lockwood 2008). 
The notion of essential skills is also highlighted, and they are defined as skills that offer a competitive edge to the organization through the execution of this skill, that is, they were built throughout time and are not easily imitated (Prahalad and Hamel 1990). Drejer and Riis (1999) point out that the skill comprehends four generic elements: technology, human beings, organization and culture.

Draganidis and Mentzas (2006) show the lifecycle of a skill: mapping, diagnosis, development and monitoring. These four stages search for continuous improvement and the development of new skills. The first phase surveys the necessary skills for the organization. The second phase analyzes the current situation of the skills and the individual proficiency. The development includes programming activities, and increasing the number and proficiency level of the skills that the employees must have. And, finally, monitoring promotes the continuous analysis of the results obtained by the other phases.

In addition to the organizational skills (Prahalad and Hamel 1990), the literature shows work-related skills (Zarifian 2001), or even skills of people in a certain organizational context (Dutra et al. 2000). In that sense, an important division is between human skills (related to the individual or the team) and the organizational skills (related to the organization as a whole) (Prahalad and Hamel 1990).

Wals (2014) analyzed the results of a report focusing on teaching and learning in all regions (Asia-Pacific, Africa, Europe, Arab region, Latin and North America), searching for a wide range of informers, such as administrators, researchers, politicians and other professionals on global, regional and local levels. The reports indicate methods and strategies used by different universities in order to become more sustainable within their contexts, in the search to develop the most specific skill for sustainability.

Universities have also created specific Chairs that approach international entities, such as UNESCO, discussing in depth the skills for sustainable development and sustainability in courses, professional development programs, activities to raise awareness in the community and continuing education for all agents of change, even the ones that intend to develop their careers outside the structure of Higher Education Institutions (Wals 2014).

Higher Education Institutions have broadened their responsibilities to introduce new ways to dialogue with society regarding sustainability. Wals (2014) highlights some of the learning methods used: the interaction between multi-stakeholders; the use of competing perspectives; diversity management according to its different aspects; inter- and transdisciplinarity; problem-based learning; value-based learning, and experiential and social learning.

A central principle is sustainable consumption in higher education, both within the campus and curriculum, and in the actions developed in the community. Sustainable consumption is understood as a consumption method in which the individuals are able to meet their main needs, maintaining ecological and socioeconomic mechanisms that are necessary for the human development and that constitute an adequate lifestyle, extrapolating the short-term perspective (Dobson 2007). Considering Higher Education for Sustainable Consumption-HESCmeans to show the severity of consumption as a source of environmental and social 
impact, in addition to incorporate the notion of individual and collective responsibility (Clark 2007).

By showing the case of the University of Bordeaux, in France, Gombert-Courvoisier et al. (2014) state that, in order to reach HESC, some pedagogical principles are necessary in order for the education of students to contemplate the solution o factual and complex problems, knowingly: considering human ecology as a pedagogical approach; treat the consumption system as a whole, considering the ecological impacts of production, supply, use and elimination methods; enable students to deal with uncertainty, with an heterogeneous audience; promote collaborative learning based on diversity; and approach complexity through interdisciplinarity. By adopting these principles, it is possible to contribute to learn key skills for sustainability, which may be seen as multifunctional individual skills independent from the context and that are fundamental to reach social and sustainability goals (Rychen 2003).

At least three approaches have been considered in relation to learning contexts: self-learning, in which the individuals build their knowledge base by themselves; social or collaborative learning, in which interaction becomes essential; and guided learning to solve actual sustainability problems (Brundiers et al. 2010; Burandt and Barth 2010; Yasin and Rahman 2011).

Developing the necessary skills for sustainability is a method of collective construction; the learning environment must offer the students incentives to implement solutions and make decisions regarding complex ecological problems, associated with changes in the consumption methods and global problems. These learning processes depend on people, skills and availability of support (Barth and Rieckmann 2012).

From the skills indicated by the theory, required within the context of sustainability, Fig. 1 sums up the skills that will be considered on this study: Thinking in a prospective manner, dealing with uncertainties; Working on a multidisciplinary environment; Searching for interconnections, independence and partnerships; Understanding transcultural cooperation for more flexible perspectives; Participation capacity; Planning and implementation capacity; Empathy, being kind and solidary; Personal and group motivation; and Understanding different behaviors and cultural perspectives (Barth et al. 2007; Wals 2014; Gombert-Courvoisier et al. 2014).

\section{Methods}

This study is classified as a case study (Yin 2015) in the University of Coimbra, Portugal, conducted from September to November 2014.

The case study was chosen as the design since it allows understanding the perspective of sustainability in the studied institution in a holistic manner. This was adequate since the focus of the analysis is a complex and contemporary social phenomenon, which requires an empirical approach, and it involves elements and 


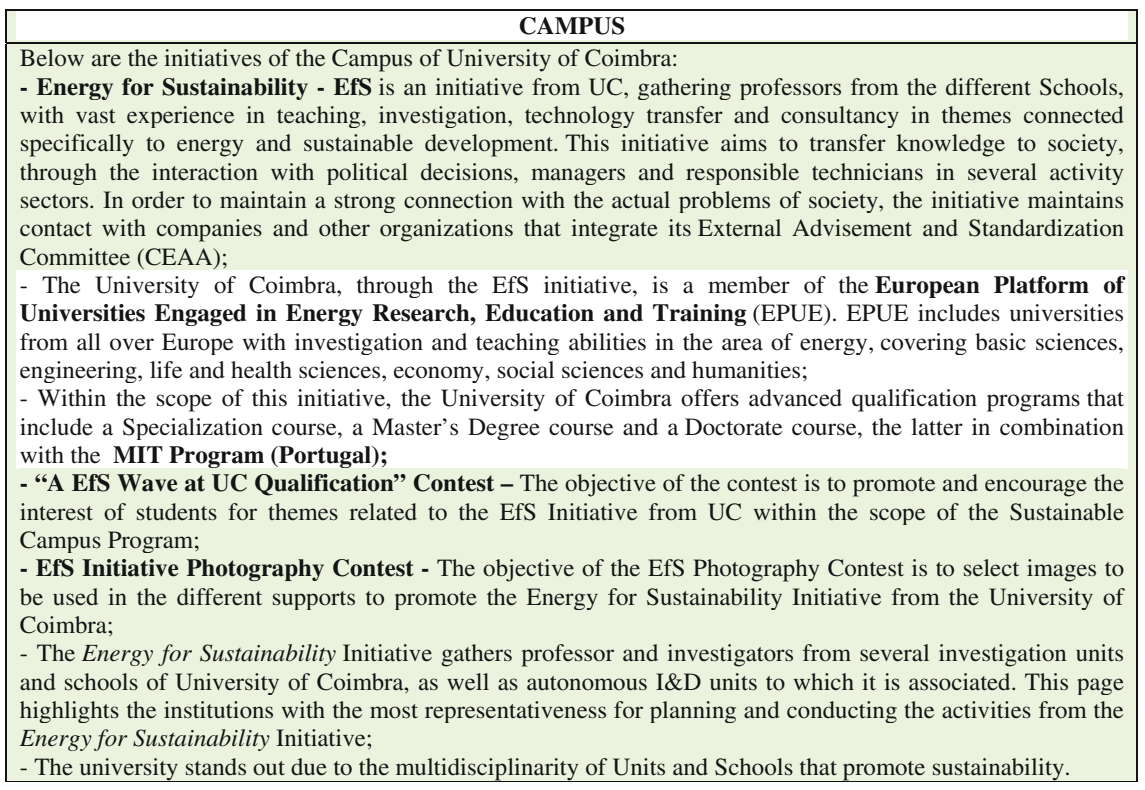

Fig. 1 Campus initiatives for sustainability at University of Coimbra. Source GREEN_UC. See more at: http://www.uc.pt/efs/green_uc

variables in relation to which it is not possible to have the necessary control using other procedures. The single case study was adopted to explore a situation in which the evaluated intervention did not have a single and clear set of results, and also because it allowed different theoretical branches to be used (Yin 2015).

In order to build the data collection protocol, observation and interview scripts were elaborated from the emerging theory on the subject. The interview was conducted with the Vice-Dean, responsible for the Strategic Planning of the Institution. The data collection occurred between September and November, 2014. The non-participant observation was chosen, in which the researcher conducts an impartial observation, and they do not participate as a member of the observe group. The analysis of documents and the institutional website was also considered as source of evidence.

In that case, the dimensions highlighted by Müller-Christ (2015) were used: campus, curriculum and community. The analysis process used as reference the Content Analysis method, defined by Bardin (2011) as a technique to read and interpret the content of any material from a verbal or non-verbal communication. This author highlights that content analysis is an investigation technique whose purpose is the objective, systemic and quantitative description of the manifested content of the communication. 


\section{Presentation and Analysis of Results}

It is important to highlight the responsibility of universities as responsibility catalyzers for society, namely because the presence of the institutions offers several benefits for companies and the local community.

Researches on the role of universities and their potential contributions for sustainable development and sustainability refer to three fundamental areas: campus, curriculum and community. The University is no longer the castrating and moralizing environment; rather, it encompasses dimensions related to society welfare, beyond the responsibilities with the campus operations, creating models that may be transferred to the community (Müller-Christ 2015).

From these three dimensions, an attempt was made to identify on the speech of the UC managers some contributions that would characterize the studied institution. Results are shown in Fig. 1.

The evidence exposed on campus as one of the differentials of the institution, from which the academic and external community have the possibility to experience a sustainability-oriented culture.

The events, contests and the European Platform of Universities Engaged in Energy Research, Education and Training (EPUE) are one of the main highlights together with the several multidisciplinary departments, focused on research in graduation and post-graduation. For Thomashow (2014), the campus is the adequate location to explore, build and practice this ethos. Elements established by the author are seen on the campus programs, such as EfS for qualification, photography contests and initiatives driven toward energy for sustainability.

Wals (2014) highlights that Higher Education Institutions have broadened their responsibilities, including new methods to dialogue with society, oriented toward learning. The author mentions the need to create new systems based on new principles, among them, sustainable consumption in higher education. The issue of water and energy consumption and the rational use of paper printing are observed on the examples mentioned on the interviews.

Below are the results for the Curriculum for sustainability initiatives at the University of Coimbra (Fig. 2).

Within the curriculum dimension, it may be observed that UC has evidence since its first Doctorate thesis in 1985 on energy efficiency; later on, in 1990, the first Master's Degree discipline on energy management was incorporated. It is noteworthy that the curriculum at UC advanced with interdisciplinary characteristics, and it is integrated and based on values, associated to participative teaching and learning methods, being able to allow critical thinking (Wals 2014) (Fig. 3).

When discussing the participation of the community on the activities of the campus, Du et al. (2013) highlight the need to create learning communities, to open the doors of the university in order to create an interaction with national, regional and local agents. The results of this aspect reveal that the University of Coimbra has 


\section{CURRICULUM}

\section{UC and Sustainability}

- The first Doctorate thesis in Portugal on energy efficiency and energy management was completed at the University of Coimbra (Department of Electrotechnical Engineering) in 1985;

- The first discipline on energy management was created in 1990 within the scope of a Master's Degree course. Before that, however, since 1979 work was being conducted at the University of Coimbra in the areas of energy efficiency and renewable energy.

- For almost three decades, UC was the home for a large number of Master's Degree and Doctorate dissertations, on themes such as:

Energy efficiency and energy management (whether on thermal energy or electrical energy, in buildings and the industry);

Sustainable buildings;

Regional and urban planning;

Electricity production planning;

Co-generation;

Demand side management (DSM);

Transformation of energy markets;

Energy network management;

Energy-environment-economy interactions;

Market liberalization processes;

Industrial ecology models integrating economic and environmental aspects of the lifecycle of products.

- In 2006, the Energy for Sustainability initiative was born, gathering around this theme a set of disciplines, Schools, I\&D units, professors and investigators;

- Over the last years, UC took several steps to potentiate energy reduction and energy efficiency, such as energy audits in several buildings, correction of the power factor or upgrade of lighting systems and electrical systems in general.

- In 2007, UC became a partner of the Green Light initiative. A project is in course to completely replace incandescent lamps by compact fluorescent lamps. An application presented by UC to replace the common fluorescent lamps of four large buildings by lighting systems with electronic ballasts and highefficiency lamps was selected by ERSE within the scope of the Energy Efficiency Promotion Plan for Electric Power Consumption;

- Students at UC regularly develop activities that are strongly connected to improving energy efficiency at the University campi, within the scope of curricular activities of Graduation or Master's Degree courses, such as projects or dissertations;

- Additionally, UC has adapted waste minimization processes for several categories. There is also a responsible hazardous laboratorial waste handling policy. This sustainability promotion strategy also involves an acquisition policy that privileges the environmental component for a growing number of them;

Fig. 2 Curriculum for sustainability initiatives at the University of Coimbra. Source GREEN_UC. See more at: http://www.uc.pt/efs/green_uc

several actions jointly with the Community. Among them are the External Advisement and Standardization Committee (CEAA), consisting of 26 companies and 5 organizations, qualification initiatives, business consultancies, projects with associated companies, in addition to being open to new initiatives and partnerships. The role of Higher Education Institutions as responsibility catalyzers for society, as local communities, companies and societies are beneficiated by the presence of universities, is such that they may intervene in the social environment, promoting sustainable development initiatives. 


\section{COMMUNITY}

- External Advisement and Standardization Committee (CEAA) - it is constituted by investigators and employers outside UC, whose role is to organize the reflection on the strategy of UC for the area of Energy for Sustainability and to evaluate the concretization of the objectives of the EfS initiative and the qualification developed within its scope;

- 26 companies and 5 organizations are currently represented at CEAA;

- EfS Initiative Meetings, Students and Companies - The Energy for Sustainability Initiative at UC promotes an annual meeting between the students from its Master's Degree and Doctorate programs, professors, companies and organizations form its External Advisement and Standardization Committee (CEAA);

- University of Coimbra (UC) - A reference in higher education and investigation in Portugal, whether due to the quality of the courses offered by its eight schools, or due to the advancements obtained in investigations on several scientific domains. The Energy for Sustainability - EfS - initiative is one of the manifestations of this policy. This initiative gathers professors from different scientific disciplines, with vast experience in teaching, investigation, transferring technology and consultancy in the areas of energy and sustainable development;

- The EfS Initiative - Objective: to respond to the challenges involved in the conception, operation and regulation of systems that produce, transport or use energy; transfer of knowledge to Society through the interaction with decisions from politicians, managers and technicians that occupy or intend to occupy positions of responsibility in the several activity sectors, involving companies and other organizations identified with their objectives;

- Advanced qualification programs - They are offered by UC, within the context of the EfS Initiative, for graduates or masters in engineering, architecture, economy and management, as well as for professionals interested on this area, in association with the MIT Portugal Program.

- Cooperation opportunities - They are offered by the EfS Initiative and are mutually beneficial between UC and companies and other organizations;

- Advanced qualification programs, namely the Doctorate in Energy for Sustainability or the Master's Degree in Energy for Sustainability. In addition to these program, shorter courses are also offered and it will also be possible to conceive on demand courses for a certain organization;

- Master's Degree and Doctorate papers within the business context;

- Support from the secretariat to recruit students that are about to complete their courses and that search for a position that allow them to apply their skills and knowledge acquired throughout the program;

- Exploring opportunities to establish joint projects for collaboration and I\&D, with the possibility of integrating the scientific work of Master's Degree and Doctorate students;

- Offering consultancy on the themes related to the EfS Initiative, such as analysis of the lifecycle of products, energy efficiency or engineering problems;

- Disclosing the EfS Initiative on the website;

- Promoting and offering services through the Innovation and Knowledge Transfer Division of UC, such as the protection of products and processes, support to financing programs, or support to the creation of technology-based companies;

- The Coordination of the Energy for Sustainability Initiative invites companies and other organizations that could be potentially interested to be part of this initiative.

Fig. 3 Initiative of the University of Coimbra for the Community. Source GREEN_UC. See more at: http://www.uc.pt/efs/green_uc

\section{Conclusions}

The role of higher education on the discussions on sustainability goes beyond the teaching/learning relationship seen on classrooms. The concept extends toward the involvement in extra-curricular projects with the surrounding community, aiming at effective solutions for the local population. Although it has a fundamental role in the development of a sustainable socioenvironmental awareness, education is not able to implement sustainability without taking concrete measures. It is up to the 
Universities to put into practice what they teach, making its own internal management a sustainable management model, also influencing with its results the organizations which their graduates will be a part of.

Within this context, from the observation of the state of the art on universities and sustainability, an attempt was made to understand how a Portuguese university develops the sustainability perspective, by analyzing the sustainability-driven skills. The references used allowed an understanding on how sustainability is applied to the studied subject matter.

The position of the studied University is in agreement with the definition of a sustainable university campus, as suggested by the current literature, which emphasizes energy saving, preservation of resources and waste reduction. Under this perspective, through its environmental management, the university has the possibility to promote equality and social justice and to extrapolate values to the entire national and global community.

The case evidence showed the aspects observed by Wright (2002) as essential aspects on a sustainable university. The sustainable campus operations, sustainable investigation, awareness of the audience, cooperation among institutions and sustainable curriculums are concerns that emerge on the publications on the website of the University.

It may be observed that the institution does not yet publish sustainability reports, with a clear disclosure of the reached goals and with the challenges and non-conforming situations. Elaborating and publishing reports could be a way to make the information more transparent and accessible to all stakeholders.

The study conducted at the Portuguese University allowed to observe complex physical and organizational structures. The issue of sustainability is a permanent challenge to the characteristic immobility of human ancestry and the characteristic scattered attention of multilevel organizations. Since it is not viable to meet all the demands of environmental sustainability nor to count on the speed of the newer institutions, the University tries, however, to take on the opportunities resulting from each threat, managing the resources considering this imperative.

\section{References}

Bardin, L. (2011). Análise de conteúdo. Lisboa, Portugal: LDA.

Barth, M., et al. (2007). Developing key competencies for sustainable development in higher education. International Journal of Sustainability in Higher Education, 8(4), 416-430.

Barth, M., \& Rieckmann, M. (2012). Academic staff development as a catalyst for curriculum change towards education for sustainable development: An output Perspective. Journal of Cleaner Production, n., 26, 28-36.

Brandão, H.P., \& de Guimarães, T. A. (2001, Jan/Mar). Gestão de competências e gestão de desempenho: Tecnologias distintas ou instrumentos de um mesmo construto? RAE-Revista de Administração de Empresas, São Paulo, vol. 41, no. 1, pp. 8-15.

Brundiers, K., Wiek, A., \& Redman, C. L. (2010). Real-world learning opportunities in sustainability: from classroom into the real world. International Journal of Sustainability in Higher Education, 11(4), 308-324. 
Burandt, S., \& Barth, M. (2010). Learning settings to face climate change. Journal of Cleaner Production, 18, 659-665.

Clark, G. (2007). Evolution of the global sustainable consumption and production policy and the United Nations Environment Programme's (UNEP) supporting activities. Journal of Cleaner Production, 15(6), 492-498.

Dobson, A. (2007). Environmental citizenship: Towards sustainable development. Sustainable Development, 15, 276-285.

Draganidis, F., \& Mentzas, G. (2006). Competency based management: A review of systems and approaches. Information Management \& Computer Security, 14(1), 51-64.

Drejer, A., \& Riis, J. O. (1999). Competence development and technology: How learning and technology can be meaningfully integrated. Technovation, 19(10), 631-644.

Du, X., Su, L., \& Liu, J. (2013). Developing sustainability curricula using the PBL method in a Chinese context. Journal of Cleaner Production, 61, 80-88. doi:10.1016/j.jclepro.2013.01.012.

Dutra, J. S., Hipólito, J. A. M., \& Silva, C. M. (2000, Jan/Abr). Gestão de pessoas por competências: o caso de uma empresa do setor de telecomunicações. RAC, 4(1), 161-176.

Edgar, W. B., \& Lockwood, C. A. (2008). Organizational competencies: Clarifying the construct. Journal of Business Inquiry: Research, Education and Application, 7(1), 21-32.

Gombert-Courvoisier, S., et al. (2014). Higher education for sustainable consumption: Case report on the Human ecology master' s course (University of Bordeaux, France. Journal of Cleaner Production, 62, 82-88. doi:10.1016/j.jclepro.2013.05.032. Last accessed March 22, 2014.

Isambert-Jamati, V. (1997). O apelo à noção de competência na revista L'orientation Scolaire et Profissionelle. In F. Ropé \& L. Tanguy (Orgs.), Saberes e competências: o uso de tais noções na escola e na empresa (pp. 103-133). Campinas: Papirus.

Müller-Christ, G., et al. (2015). The role of campus, curriculum, and community in higher education for sustainable development-A conference report. Journal of Cleaner Production, 62, 134-137. doi:10.1016/j.jclepro.2013.02.029. Accessed March 17, 2014.

Prahalad, C. K., \& Hamel, G. (1990, May/June). The core competence of the corporation. Harvard Business Review, 68(3), 79-91.

Rychen, D. (2003). Key competencies: Meeting important challenges in life. In D. Rychen \& L. Salganik (Eds.), Key competencies for a successful life and wellfunctioning society (pp. 63107). Cambridge: Hogrefe \& Huber.

Thomashow, M. (2014). The nine elements of sustainable campus (p. 2014). USA: Massachusetts Institute of Technology.

UNESCO. (2014). United Nations Educational, Scientific and Cultural Organization. Shaping the future we want: With the support of UN Decade of Education for Sustainable Development (2005-2014); final report. Paris, France.

Vilches, A., et al. (2012). The need for contributions to the decade of educate for a sustainable future: An ethical commitment. In W. Leal Filho (Ed.), Environmental education, communication and sustainability. Frankfurt: Peter Lang.

Wals, A. E. J. (2014). Sustainability in higher education in the context of the UM DESD: A review of learning and institutionalization processes. Journal of Cleaner Production, 62, 8-15. doi:10. 1016/j.jclepro.2013.06.007. Last accessed March 22, 2014.

Wright, T. (2002). Definitions and frameworks for environmental sustainability in higher education. International Journal of Sustainability in Higher Education, 3(3), 203-220.

Yasin, R. M., \& Rahman, S. (2011). Problem oriented project based learning (POPBL) in promoting education for sustainable development. Procedia Social and Behavioral Sciences, 15, 289-293.

Yin, R. K. (2015). Estudo de caso: planejamento e métodos (5th ed.). Porto Alegre: Bookman. Zarifian, P. (2001). Objetivo competência: Por uma nova lógica. São Paulo: Atlas. 


\section{Authors Biography}

Thiago Antonio is Beuron Administration Professor at the Federal University of PampaUNIPAMPA - RS. Doctor in Business Administration from the Post-Graduate in Business Administration from the Federal University of Santa Maria-PPGA-UFSM, participated in the Scholarship Program Institutional Doctoral Sandwich abroad-PSDE at the Faculty of Economics, University of Coimbra-FEUC, Portugal. Master in Business Administration from PPGAUFSM (2012). Bachelor in Business Administration from the State University of the MidwestUNICENTRO - PR (2009). He has experience in the area of Administration, emphasis in Strategy and Organizational Behavior. A member of the research groups: Research Group Management and Organizations Collective-UFSM; Studies and Research in Strategy, Innovation and Sustainability-UFSM.

Lucas Veiga Ávila is Professor of the State University of Rio Grande do Sul Assistant-UERGS; Postgraduate Course Coordinator-Specialization in Leadership and Sustainability, Group Leader of the Research: Management and Organizational Development at the University Unit UERGS; $\mathrm{PhD}$ in Administration at UFSM. Magazine Executive Director of Management and Organizations Cooperatives-RGC. A Masters in Business Administration from Universidade Federal de Santa Maria-UFSM. Specialist in Strategic Business Management for Integrated Regional UniversityURI. Degree in Business Administration from Universidade Regional Integrada-URI. Research on issues involving: environmental management; sustainability; Quality Management and Environmental production; public administration; Public planning; planning and Universities.

Luciana Londero Brandli is graduated in Civil Engineering (1995), master's degree in Civil Engineering (1998) and Ph.D. in Production Engineering (2004). Pos Doctorial Research at Hamburg University of Applied Sciences (2014). She is currently Associate Professor in the University of Passo Fundo, south of Brazil, working in the Master Program in Engineering, Infrastructure and Environment. Her current research interests include sustainability in high education and green campus, environment management, management of urban infrastructure, sustainable cities and green buildings.

Filipe Jorge Ribeiro Almeida graduated in 1997 in Organization and Management from the Faculty of Economics, University of Coimbra (FEUC). In 2001 he held the Master in Business Administration with specialization in Business Strategy, by FEUC. In 2008 he obtained equivalence to Doctor Degree in Business Administration, with specialization in strategy, the FEUC. It is a teacher of the Faculty of Economics, University of Coimbra since 1997 in undergraduate programs, masters, MBA and PhD. Disciplines taught: Ethics and Corporate Social Responsibility (regency), Business Ethics (regency), Organizational Behavior (regency), Human Resource Management, Financial Accounting, Marketing and Introduction to Management.

Lúcia Rejane da Rosa Gama Madruga graduated in Business Administration from Universidade Federal de Santa Maria (1988), Full Degree in Mathematics-Franciscan University (1984), master's degree in Production Engineering from the Federal University of Santa Maria (1994) and doctorate degree in Agribusiness from the Federal University of Rio Grande South (2009). He is currently an adjunct professor at the Federal University of Santa Maria. It has experience in university governance and works in administration, with an emphasis on people management, public management, agribusiness, sustainability, environmental responsibility and social learning.

Eduardo Jorge Gonçalves Barata Is Assistant Professor of the Faculty of Economics, University of Coimbra. MSc in Financial Economics University of Coimbra, Portugal. Degree in Economics, University of Coimbra, Portugal. 